\title{
El lenguaje visual innovador de Pere Joan: el pictograma analógico frente a la cultura digital en el cómic español contemporáneo
}

\author{
Benjamin Fraser
}

Department of Spanish and Portuguese, College of Humanities, University of Arizona, Tucson, USA

\begin{abstract}
O
Este artículo explora la creación de un lenguaje icónico innovador por parte del artista gráfico Pere Joan en su obra 100 pictogramas para un siglo (XX) (2014). Su trabajo crítico-visual refleja el estatus contemporáneo de los emoticonos y los emoji, signos de una creciente integración de lo digital en la vida cotidiana. Entendido a la luz de la producción reciente del artista, el lenguaje analítico visual de Pere Joan funciona como una aceptación de las posibilidades formales señaladas por lo digital y a la vez como una reivindicación de la cultura analógica y la reflexión histórica. Además, la estructura innovadora de las páginas del libro pone de manifiesto la relación entre el cómic y el arte gráfico puro. Al fin y al cabo, más que una celebración de la era digital, 100 pictogramas recupera un impulso ensayístico analógico para recalcar el potencial crítico de toda imagen. Desde el minimalismo formal, eco gráfico de los emoticonos, Pere Joan hace posible una toma de conciencia histórica que simbólicamente llevará a los lectores más allá de la inmediatez sugerida por la lógica del consumo hacia una crítica de la vida cotidiana.
\end{abstract}

\section{ABSTRACT}

This article explores graphic artist Pere Joan's creation of an iconic, innovative language in his work 100 pictogramas para un siglo (XX) (2014). His critical-visual work reflects the contemporary status of emoticons and emoji, signs of the digital's increasing integration in everyday life. Understood in light of the artist's recent production, Pere Joan's analytical visual language functions to underscore the formal possibilities signaled by the digital and at the same time to vindicate analog culture and historical reflection. Moreover, the innovative structure of the book's pages highlights the relationship between comics and graphic art proper. In the end, more than celebrate the digital, 100 pictogramas recovers an analogic, essayistic impulse in order to stress the critical potential of all images. Within a formal minimalism, a graphic echo of emoticons, Pere Joan makes an historical awareness possible that will symbolically carry readers beyond the immediacy suggested by consumeristic logic toward a critique of everyday life.
PALABRAS CLAVE

Pere Joan; arte gráfico; epistemología visual; cultura digital; emoticonos; iconicidad; cómic; España

\section{KEYWORDS}

Pere Joan; graphic art; visual epistemology; digital culture; emoticons; iconicity; comic; Spain 



\section{Introducción}

Aunque la producción artística de Pere Joan (1956 -) todavía no ha recibido la atención que merece, la crítica sí ha reconocido su importancia en el campo de la historieta española. ${ }^{1}$ Se reconoce al artista mallorquín por su trabajo en proyectos que datan de La Movida; un movimiento del cual la revista El Víbora tal vez haya quedado como máximo representante (Compitello 2014; Vilarós 2002). Pero Pere Joan es reconocido también por sus colaboraciones e innovaciones como artista y además como editor (Bufill 1994; Conget 2004; de Guereñu and Manuel 2011; Dopico 2005; García 2010; Lladó Pol 2012). Recientemente, por ejemplo, el artista ha trabajado con el escritor post-poético Agustín Fernández Mallo en una serie de comics que aparece en Nocilla Lab (2009)-el tercer volumen del proyecto Nocilla que además incluye Nocilla Dream (Fernández Mallo [2006] 2010) y Nocilla Experience (2008) (véase Barker 2010, 2014; Fraser 2012)-y además ha editado una versión de Nocilla Experience (Pere Joan 2011) en forma de novela gráfica (Fraser 2016; Gutiérrez García Huidobro 2014). Más allá de las referencias al artista que surgen por un momento y luego se desvanecen en los análisis que se enfocan más sobre Fernández Mallo (Henseler 2011a, 2011b; Saum Pascual 2014), es fácil que los lectores interesados encuentren su nombre hasta en las historias más breves del cómic en España, muchas veces al lado del nombre de su colaborador temprano, Max (Bufill 1994; Conget 2004; de Guereñu and Manuel 2011; García 2011; Lladó Pol 2012; Pons 2013). ${ }^{2}$ El presente ensayo se atreve a corregir esta situación empobrecedora, enfocándose en una obra específica y reciente del artista que es la que mejor demuestra el carácter ambiciosamente innovador de sus contribuciones gráficas.

Cómic y arte gráfico a partes iguales, 100 pictogramas para un siglo (XX) (2014) consta de 121 páginas enumeradas que ponen en tela de juicio la capacidad del artista para emplear la imagen como vehículo de una reflexión histórica y un pensamiento crítico profundos. Aquí Pere Joan une su interés en temas sociales con la rebeldía formal establecida en sus obras de los ochenta (véase Pons 2013, 77). ${ }^{3}$ El lenguaje visual que emplea el artista es característicamente condensado y nítido. Como señala el mismo título de la obra, los resultados de su esfuerzo son los 100 pictogramas mismos. Estos caben bien en una sola página, al principio del índice (véase figura 1), y se reproducen además en la contraportada del libro en una tabla compuesta por imágenes organizadas en diez filas y diez columnas. Dado el tamaño compacto de estas imágenes y el hecho de que usan una forma básica e icónica de representación, se puede deducir que la creciente familiaridad de los lectores con los emoji que inundan sus móviles facilita la interpretación de los pictogramas. En concreto, la iconicidad-propiedad inherente a toda muestra de arte secuencial (McCloud 2009) y además una parte crucial de la comunicación por internet desde sus orígenes (Wyss 1999)-ayuda a los lectores a interpretarlos. Al concentrarse en la página-tabla de pictogramas, se distinguen inmediatamente-gracias a la iconicidad-varias formas visuales. Por ejemplo, hay objetos de la vida cotidiana como un reloj, una camiseta, un coche, una cámara fotográfica; hay símbolos lineal-geométricos como la esvástica, la señal de paz, o los dibujos 'masculino'/'femenino'; y hay representaciones del cerebro, el corazón, y la figura humana. Reconocer algunos de los pictogramas requiere que los lectores posean una educación artística básica: aparecen el retrato de la Mona Lisa con bigote, el reloj semi-fundido de Dalí, y el soldado caído icónico fotografiado por Robert Capa. Pero que 


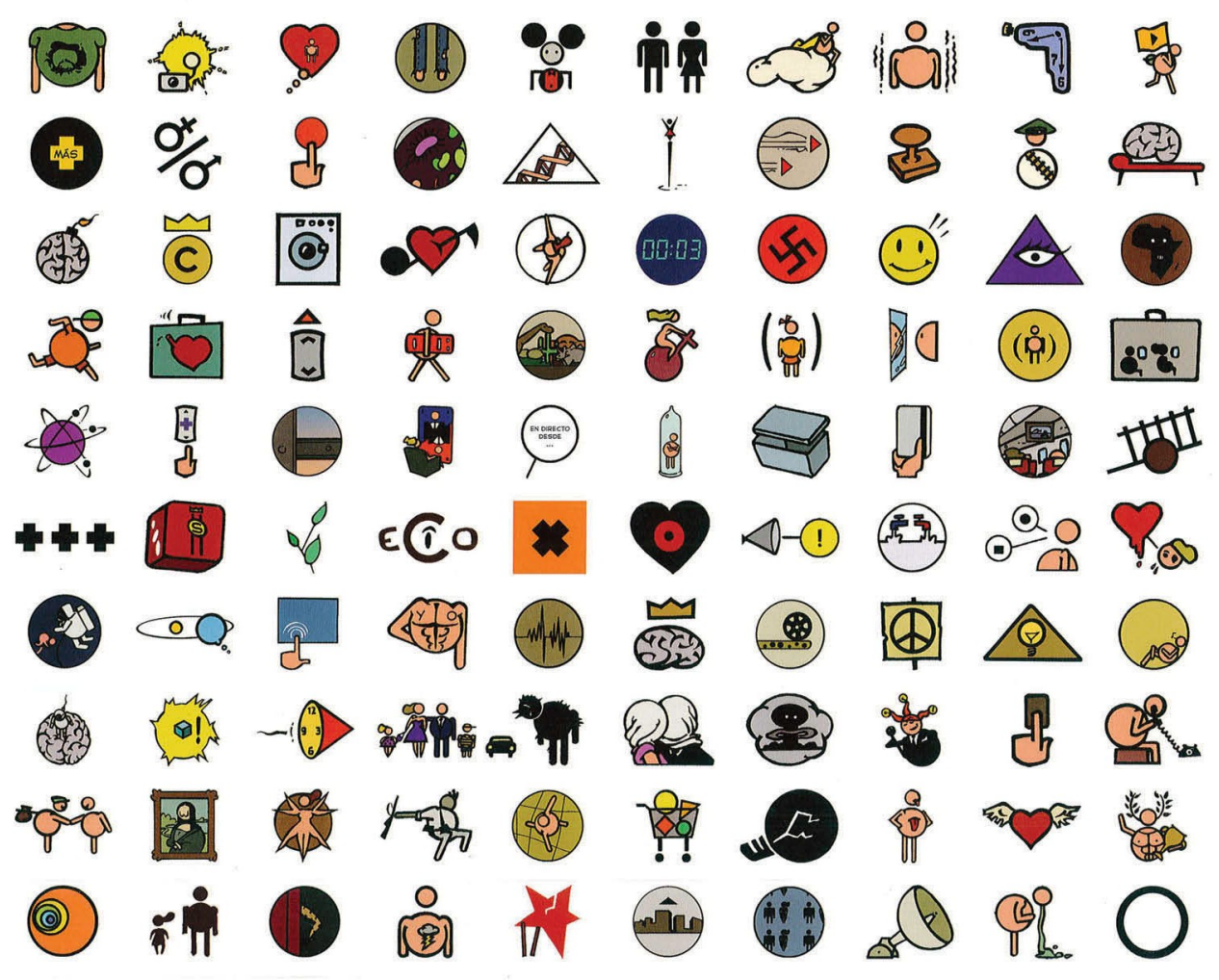

Figura 1. Los 100 pictogramas.

una persona sea capaz de descifrar los objetos que figuran en los pictogramas gracias a una iconicidad rudimentaria - socializada o no-no quiere decir que entienda su significado. Todas las imágenes requieren explicaciones. Y las explicaciones presentadas por Pere Joan exigen una reflexión profunda que va más allá del mero entretenimiento.

Es aquí-al nivel de las explicaciones-donde yace la proeza de 100 pictogramas. El libro de Pere Joan cumple una función intelectual y auto-consciente muy parecida a la que persigue Ana Merino en su obra de crítica El cómic hispano. Pero si Merino 'propone una interpretación de los cómics como factor cultural capaz de representar la modernidad masiva y popular del siglo XX' (9), Pere Joan utiliza el método representacional del cómic - ya como factor cultural y como objeto analógico-para interpretar la modernidad masiva y popular del siglo XX. Así se asemeja a un ensayo crítico en forma de cómic. Sin duda, Pere Joan emplea elementos del arte secuencial, pero 100 pictogramas no es un cómic narrativo. Una página típica incluye un pictograma solo, situado hacia arriba y muy cerca al margen izquierdo, acompañado por una palabra o una frase que ayuda a su identificación. Lo que queda de la página-en realidad la mayoría de su espacio-esboza una explicación, demuestra una elaboración o indaga más a fondo en el tema sugerido por el pictograma-imagen. Esta área de la página puede (o no) ser estructurada por la calle (o, en estudios anglófonos del cómic, el gutter)-el espacio entre los paneles que uno suele encontrar en el cómic convencional y que estimula el tiempo y movimiento. Muy a menudo no hay ninguna calle-aspecto discutido en la 
segunda sección de este ensayo, la cual presenta una tipología de las estrategias innovadoras de Pere Joan en esta obra-sino más bien una serie de imágenes agrupadas aquí y allá. Estas imágenes aparecen contra un trasfondo monocolor que sugiere el espacio superficial y expansivo de una pantalla digital. De esta manera, 100 pictogramas para un siglo $(X X)$ rompe varios aspectos asentados del arte secuencial convencional; no sólo juega con la estructura convencional del cómic al empujar este más allá de la composición en calles/paneles, también esboza un formulario para una dirección intelectual, analítica e histórica del cómic español. Su creador reflexiona sobre la relación compleja entre iconicidad y significado sugiriendo la continuada relevancia de un pensamiento profundo en el siglo XXI-uno que es consciente del legado histórico de los acontecimientos del siglo XX.

Todo en 100 pictogramas parece ser organizado como si Pere Joan-inspirado por los emoji y los emoticonos como símbolos de la era digital en nuestra cultura-trasladara la lógica digital de los emoticonos a un medio de arte decididamente analógico. Al plasmar sus ideas en un cómic, pretende tomar un inventario de nuestro siglo XX artística e históricamente. El resultado sugiere que el verdadero tema del libro es la intersección de la tecnología y el conocimiento. Lo que logra hacer 100 pictogramas es sintetizar lo mejor de la cultura analógica con la forma de la cultura digital en un producto visual. Esto lo hace a través de admitir y hasta sostener la hegemonía de la comunicación rápida y digital en la forma de una serie de pictogramas. Pero al construir estos pictogramas a mano (y no en computadora) y al publicarlos en un libro impreso y por ende físico, Pere Joan reafirma que el impacto cultural y la fuerza crítica de la imprenta analógica continúan en el siglo veintiuno.

Elaborando esta tesis, la primera sección del presente artículo, 'Del pictograma al emoticono y el emoji: la venganza de lo analógico' afirma el papel contradictorio de la imagen en nuestro tiempo cultural y digital. Como escribe Johanna Drucker (2014), es preciso que entendamos la imagen usando una perspectiva que enfatice la epistemología visual. Las imágenes, subraya la autora, requieren una interpretación humanística. Es importante también considerar que la herencia de los emoji nos conduce, a través de los emoticonos que los anticiparon, a una forma visual iniciada en el contexto de la imprenta analógica. Aquí se introduce la discusión de la distancia percibida entre la cultura de la imprenta y la cultura digital tal como lo explica la crítica N. Katherine Hayles (2012). Hasta cierto punto, la obra de Pere Joan demuestra - siguiendo a Hayles - la complementariedad de las culturas de la imprenta y de la época digital. La segunda sección, titulada 'Tipología: variantes en la composición de 100 pictogramas,' sugiere una tipología que cataloga las diferentes estrategias visuales empleadas por Pere Joan en el libro: la composición lineal, la composición por calles, la composición sin palabras y la composición estilo página. Esta tipología es necesaria para entender la innovación del artista en el campo de la expresión visual, pero también presenta la oportunidad para señalar la variación temática del cómic. La conclusión concisa que sigue vuelve a hacer hincapié en 100 pictogramas como una fusión de lo analógico y lo digital.

\section{Del pictograma al emoticono y el emoji: la venganza de lo analógico}

En su libro Graphesis: Visual Forms of Knowledge Production (2014), Johanna Drucker subraya la falta de atención dirigida hacia la epistemología visual y dilucida la función de 
la imagen como representación del conocimiento. Por un lado, al efectuar la visibilización de cosas e ideas no visibles, la representación sugiere el poder totalizador del conocimiento, el cual pretende ejercer un dominio completo sobre la vida humana. Por otro lado, escribe Drucker, sabemos que hay mucho en la vida contemporánea que una imagen no puede representar $(2014,22)$. Es verdad que las imagenes pueden simplificar la complejidad de la vida, pero también es cierto que nos resistimos a las contribuciones de formas visuales del conocimiento $(2014,23)$. No obstante, para Drucker como para nosotros, es innegable que las imágenes median nuestra experiencia con frecuencia en el siglo veintiuno $(2014,16)$. Más y más a lo largo de los capítulos de Graphesis, los análisis que presenta Drucker tienden a reforzar su intento de desnaturalizar nuestra experiencia de imágenes (2014, 125). Enfatizan lo que la autora llama 'constructedness' como una propiedad decisiva de las imágenes, y con ello, la necesidad de utilizar la interpretación humanística para entenderlas todas $(2014,125)$. A pesar de las sospechas lanzadas en contra de la imagen, fácilmente identificadas en la cultura moderna, lo visual desempeña una parte importante de las tradiciones humanísticas del conocimiento.

Como bien sugiere Drucker, un análisis del pictograma desde una perspectiva arraigada en la historia del arte, y que pone énfasis sobre la epistemología visual, no ha sido producido todavía $(2014,17)$. Los libros que sí prestan atención al fenómeno no cuadran con la meta del presente trabajo (véase por ejemplo Abdullah y Hübner 2006). Pero lo que sí importa e interesa por el momento es el uso del pictograma en esta obra de Pere Joan y el eco implícito que hace de una tradición digital que evoluciona desde el emoticono al emoji. Al entender 100 pictogramas para un siglo (XX) en términos de la representación analógica de lo digital, llegamos a apreciar cómo efectúa el artista gráfico una especie de détournement para la que el medio del cómic resulta ser muy apta. ${ }^{4}$ En el proceso, descubrimos los antecedentes del emoji en los tempranos emoticonos, los cuales demuestran una notable herencia analógica en sí. Tomando en cuenta los comentarios de Drucker, Pere Joan recurre a una forma visual de conocimiento que requiere interpretación humanística precisamente para problematizar lo visual y combatir nuestras sospechas de la imagen. En su cómic atrevido, el artista mallorquín critica la subordinación del conocimiento histórico e intelectual a la cultura superficial de la imagen vigente hoy en día en la sociedad de consumo contemporánea. Aún más interesante es el hecho de que Pere Joan utiliza el lenguaje digital para llevar a cabo su crítica en un contexto analógico.

Los lectores que poseen smartphone admitirán inmediatamente el poder visual de los emoji que usan diariamente al textear. Pero tal vez desconozcan la historia de los emoticonos que los han precedido, y posiblemente no hayan considerado su conexión con la cultura de la imprenta. Lo que es interesante en sí es que la historia del emoticono está asociada con la historia de la puntuación. ${ }^{5}$ Como bien notan Maja Katarina Tomić, Martinez, y Vrbanec (2013), la pre-historia de los emoticonos se remonta al siglo diecinueve cuando estos solían comunicarse a través de secuencias del alfabeto del código morse; los emoticonos aparecían en forma tipográfica en la imprenta analógica, y a veces en las creaciones de figuras literarias $(2013,35-36) .{ }^{6}$ El nombre 'emoticono' viene de la combinación de las palabras 'emoción' e ‘icono,' por lo cual no debe sorprender que en el desarrollo histórico de los emoticonos entendidos como práctica social haya predominado la representación icónica. ${ }^{7}$ Al trasladarse delcontexto 
tipográfico impreso al contexto digital con la llegada de internet, los emoticonos se han multiplicado y diversificado sin parar al convertirse en los emoji. Muchos de los primeros emoticonos tipográficos impresos representaban expresiones de la cara humana (i.e.:-), $(-,:$ D. . .), y con el tiempo han pasado a reforzar la tendencia hacia la práctica de la personalización que ahora existe en los media digitales (Hjorth 2009a, 65). ${ }^{8} \mathrm{Al}$ trazar el sendero inverso - eso es, al trasladar una lógica digital a un espacio analógico-la obra de Pere Joan claramente se aprovecha de este tipo de conexiones icónicas con la forma y la personalidad humanas cuando hace sus pictogramas de tamaño reducido. ${ }^{9}$

Las páginas de 100 pictogramas demuestran el hecho de que la capacidad para el pensamiento profundo no es reducida automáticamente sólo por la irrupción de una nueva forma de tecnología o formas de comunicación simbólicas que se basan en la imagen. En pleno auge de la sociedad de la imagen y del espectáculo, Pere Joan rescata el valor de este tipo de pensamiento profundo. Empezando con unas semillas del pensar visual (las imágenes de tamaño uña), el artista despliega su significado socio-cultural e histórico en un espacio extendido de pura significación. De esta manera, 100 pictogramas produce dos tipos de espacio: el espacio del icono y el espacio de su explicación. La representación estética condensada de un lado, y el trasfondo de otro. Cadena de signo y significado. En vez de reaccionar con miedo y sarcasmo frente a una revolución tecnológica en la comunicación-en inglés el término adecuado sería 'computermediated communication' (CMC) - Pere Joan efectivamente reivindica la importancia epistemológica de las imágenes icónicas y sugiere la necesidad de su interpretación humanística.

Al adaptar la forma de los emoticonos digitales en un contexto impreso, lo que nos presenta el artista en las páginas de su libro es una forma de computación analógica. Es decir, Pere Joan crea una confrontación artística entre dos formas de conocimiento que progresivamente se han distinguido la una de la otra con el desarrollo del mundo digital. Adaptando la terminología usada por N. Katherine Hayles en How We Think: Digital Media and Contemporary Technogenesis (2012), el primero es un conocimiento profundo pero limitado, basado en estrategias de lo que Hayles, entre muchos otros humanistas de campos de literatura, llama close reading. ${ }^{10} \mathrm{El}$ segundo es un conocimiento amplio pero hábil, basado en estrategias de hyper reading que surgen con la red y sacrifican profundidad para posibilitar extensión y agregación. ${ }^{11}$ De un lado va un conocimiento asociado con la imprenta analógica, y de otro un conocimiento-o mejor dicho, una estrategia-asociado con la época digital. Como bien nota Hayles en su estudio, los dos métodos de buscar conocimiento se complementan: juntos, cubren un territorio profundo y ancho con un enfoque preciso y un alcance extensivo.

Las imágenes de Pere Joan se asemejan a la forma y la apariencia de los emoticonos o los emoji y, por lo tanto, constituyen una reapropiación del conocimiento digital en forma analógica. En términos de la interpretación humanística de Drucker, estas imágenes sirven como iconos relativamente superficiales de unas ideas concretas cuyos significados residen no necesariamente en sí mismos sino que son producidos en el momento de actualizarse en el discurso comunicativo de la página del cómic. Pere Joan no está contento con la representación condensada de ideas en la forma de imágenes que es una característica clave del siglo XX; además, las descifra y las contextualiza históricamente a través de una innovación formal relacionada con el mundo artístico del cómic. Logra esta operación meditativa en un espacio monocolor y en la 
mayoría de los casos en un espacio sin calles (sin espacio blanco entre viñetas), lo cual produce un efecto que se asemeja al espacio de una pantalla digital. ${ }^{12}$ Para volver a la obra de Hayles citada arriba, Pere Joan construye su obra-tanto en forma como en contenido - con atención puesta a la existencia de 'mindsets formed by print, nurtured by print and enabled and constrained by print' $(2012,1)$. De esta manera, el artista contribuye al debate contemporáneo de una sociedad que batalla con el problema de cómo empalmar dos formas de lectura: la lectura digital con la lectura analógica (Hayles 2012, 56). ${ }^{13}$ Finalmente, 100 pictogramas sutura un énfasis en la iconicidad digitaladecuada, apretada, condensada, y tal vez superficial — con un conocimiento analógico - profundo y detallado, capaz de pensar y evaluar el legado de los acontecimientos históricos del siglo XX. En el proceso, no sólo reivindica el medio del cómic como un instrumento de crítica y de reflexión histórica, también contribuye a lo que David Sax (2016) ha llamado The Revenge of Analog que se despliega en el siglo veintiuno digital. ${ }^{14}$

\section{Tipología: variantes en la composición de 100 pictogramas}

Basta una consideración breve de cuatro muestras categóricas para entender cómo Pere Joan realiza un pictograma icónico y luego articula su significado histórico en una página impresa que sugiere la forma estética del conocimiento digital. Los ejemplos escogidos demuestran una variedad de estrategias de representación visual, pero es necesario decir que no captan completamente el humor ligero y hasta cierto punto incomunicable de algunas de sus imágenes, y aún menos la impresión cumulativa que viene de leer todas de una vez, página por página, desde la portada a la contraportada. Los ejemplos aislados documentados aquí abajo tampoco comunican el peso incremental de la perspicacia de Pere Joan. Pero sí demuestran el ojo único y la innovación formal que caracterizan la reputación de este artista heterodoxo, pensador, y contemplativo.

Además, todos estos ejemplos innovadores contribuyen a la necesidad, documentada por Jesse Cohn (2009), a que nos fijemos en la página del cómic (y no la lógica lineal del cómic entendido sólo como secuencia de paneles) como unidad estructurante del arte gráfico. ${ }^{15}$ Como no hay espacio en un artículo de extensión limitada para analizar a fondo un libro de tanto contenido variado, los subsecuentes análisis se concentran en dos aspectos interrelacionados de 100 pictogramas: 1) el diseño gráfico y la forma artística de sus páginas impresas, y 2) una cierta invocación intelectual del pictograma visual analógico (y del cómic material). Juntos, estos dos aspectos contribuyen a desnaturalizar la imagen e inducir a los lectores a pensar más profundamente no sólo sobre la representación visual como base para el conocimiento sino también sobre la sociedad contemporánea. En las subsecciones tituladas 'La composición lineal,' 'La composición por calles,' 'La composición sin palabras,' y 'La composición estilo página,' subrayo la originalidad gráfica del artista mallorquín e intento sugerir la variedad de temas abarcados en el cómic.

\section{La composición lineal}

Una de las estrategias formales más frecuentes de Pere Joan en este libro es la anulación de la calle tan característicamente usada en el cómic (véase McCloud 2009, capítulo 3 'Sangre en la calle'). Es cierto que el libro comienza y termina con muestras de arte 
secuencial más tradicional (McCloud 2009, 7-8, 118-21), y también que aparece la calle en algunas páginas que tampoco carecen de sus propias innovaciones formales (mencionadas en la próxima sección de abajo). Pero en la mayoría de los casos, Pere Joan prefiere evitar su uso. Opta por la libertad trasmitida por el espacio abierto de un gran cuadrado monocolor. Sin embargo, muchas veces continúa una tradición de lectura que sigue el movimiento lineal izquierdo-derecho, habitual en el oeste, en este mismo espacio monocolor de libertad.

Un ejemplo es ‘Encontrarse a sí mismo’ (\#1, Pere Joan 2014, 16), el primer número de los cien incluidos en el libro y además el primer pictograma en la sección titulada

'Individualismo,' compuesta por siete pictogramas. El icono del pictograma mismo incluye dos figuras, están de pie y participan en un apretón de manos. La figura a la izquierda representada con un sombrero y una mochila encarnan dos tipos de viajeros

los dos de tipo viajante. La explicación del icono que se plasma en el espacio pantalla color verde consiste en cuatro imágenes. Se lee una definición impresa como superíndice respecto a las imágenes: 'Salir a buscar la propia identidad, a encontrarla

en otro sitio.' En la primera imagen se ve a un hombre en casa con una marca interrogativa cerca en el aire. La segunda retrata a un hombre caminando por una puerta a la derecha, ahora con sombrero y mochila. En la tercera, el hombre se sienta en una roca, su mochila en la tierra; un primer plano de su mano en forma de círculo nos indica que el hombre hace dedo en una carretera. En la cuarta imagen, vemos el pictograma mismo, con la diferencia de que aquí se añade círculos-burbujas que con flechas nos indican 'él,' ‘el auténtico' y 'el nuevo, el mismo.' La multiplicación textual del ego de una persona individual tiene su propio humor al nivel del contenido, pero es menester decir que hay un leve humor también en la forma de representar sus figuras.

Aquí, como en otras muchas páginas del libro, la cantidad de espacio vacío en las explicaciones de los pictogramas les presta una distancia lectoral, reduciendo el tamaño de las figuras representadas y frecuentemente aumentando la ridiculez de sus acciones y aspiraciones. En 'Encontrarse a sí mismo,' este espacio vacío confirma lo ridículo del título del pictograma, de la imagen del pictograma en sí, y también del viaje aparentemente sin sentido del hombre retratado. En la explicación de este pictograma, yen esta sección (véase también el pictograma \#3, 'Yo'), Pere Joan se burla del egoísmo que para él caracteriza el siglo XX, a la vez que lo reconoce como una parte innegable de nuestro mundo contemporáneo. Es posible sentir una especie de futilidad crítica en sus figuras, en las acciones que ejercen, y en el espacio que todo lo envuelve en la explicación. ${ }^{16}$ Pero es importante subrayar que en el pictograma mismo, una representación minimalista de la idea, aun con el título incluido hacen falta el humor ligero y la crítica social leve que se manifiestan en la explicación.

\section{La composición por calles}

La separación entre viñetas conocida como la calle es una herramienta y propiedad fundamental del cómic tradicional. Como bien documenta Scott McCloud, la calle requiere la participación activa del lector para lograr clausura, lo que diferencia el cómic del cine y otras representaciones mediáticas. En Entender el cómic, escribe McCloud que 'en el limbo de la "calle", la imaginación coge dos imágenes separadas y las convierte en una sola idea,' y que 'la clausura nos permite conectar esos momentos 
y construir mentalmente una realidad continua y unificada' (McCloud 2009, 66, 67). El arte secuencial procede por medio de transiciones, que suelen ser más o menos convencionales. Aunque no hubo calles en el ejemplo de 'Encontrarse a sí mismo' discutido arriba, el formato lineal de su explicación todavía procedía según una cadena de acciones en unos momentos temporales determinables y definidos. ${ }^{17}$ Pero en 100 pictogramas, predomina un tipo de transición que McCloud cataloga como aspecto- aaspecto. Esta transición 'suele pasar por alto el tiempo, recreándose en diferentes aspectos de un lugar, idea, o disposición de ánimo' (McCloud 2009, 72). Las transiciones aspecto-aaspecto, en el caso de Pere Joan, son imprescindibles para apoyar el mensaje históricoanalítico de sus secuencias que aparece en el texto explicando cada pictograma.

Se puede observar en muchas páginas del libro cómo las imágenes, en su forma y contenido, se articulan cabalmente con la definición presentada en forma de texto ( $p$. ej. \#12 'Antiantropocentrismo,' \#48 'Turismo,' \#61 'Cruz gamada,' \#62 'El hongo atómico,' y \#66 ‘África’ [Pere Joan 2014, 29 62, 76, 77, 80]). Pero el ejemplo de 'Cruz gamada' (\#61, Pere Joan 2014, 76), el cual consiste en ocho paneles separados por las calles tradicionales del cómic, es uno de los más llamativos, tanto por su importe histórico como por su estética. El pictograma en sí es, naturalmente, una representación del signo del nazismo en negro contra un trasfondo de rojo-el mal simbólico del siglo XX en todo occidente. El texto parece funcionar bien sin imágenes, al ser una crítica de la máquina propagandística de los nazis. ${ }^{18}$ Una oración se nos presenta en cada uno de los ocho paneles, con la excepción del último panel que contiene las dos oraciones finales. Así, el texto breve encapsula toda una perspectiva crítica histórica-aunque popularmente reconocida también, digerida por el público por medio de todo un legado de programas mediáticos de ficción y no ficción-sobre el nazismo que sutura su violencia despreciable y la cultura elegante de su look.

Pero las imágenes también comunican el mismo mensaje que el texto. El primer panel demuestra el pictograma en el centro del marco, con un cráneo negro detrás, parcialmente escondido y simbolizando la muerte y el mal. La cruz gamada figura en cinco de los ocho paneles, estableciendo un ritmo visual, mutándose e incorporándose a varios objetos - de esta forma representa visualmente la lamentable filtración de la ideología nazi en una variedad de contextos oficiales y cotidianos. En el segundo panel que menciona el siglo $X X$ se destacan una ' $X$ ' $y$ una cruz gamada en negro contra un trasfondo rojo en una estética abstracta, mimetizando la doble equis que los lectores asociarán con el siglo XX desde el título de 100 pictogramas para un siglo (XX) a las últimas páginas del libro. En la parte de arriba hacia el borde superior del tercer panel, con un trasfondo monocolor negro, se ven unos focos que iluminan un telón rojo en el que aparece la figura de la cruz gamada ahora separada en sus componentes, dos ' $\mathrm{S}$ '. En los paneles seis y ocho aparece la cruz gamada en banderas, un estandarte y un altavoz. Mientras que los paneles cinco y siete continúan con un ambiente oscuro e imágenes militares que implican terror y violencia. Más interesante aún es el panel cuatro donde el color del trasfondo cambia a verde y bajo el texto 'Porque existen otros holocaustos menos referenciados' el artista retrata un pequeño montón de calaveras. La presencia de verde y la ausencia del esquema rojo/negro es un momento de respiro y punto de contraste que permite al lector meditar sobre la violencia en otros contextos, antes de fusionarse otra vez con la estética y la violencia característica del nazismo en la 
imaginación popular. El altavoz y la mención de taquilla en el último panel, con la ecuación final casi banal y resignada 'El mal + buenos publicistas' resume en buena forma el contraste entre una violencia horripilante, deshumanizadora y excepcional y una estética superficial pero mundanal y de intención elegante. Como bien dice McCloud comentando su función general en el cómic, aquí las transiciones aspecto- aaspecto pasan por alto el tiempo y se recrean en diferentes aspectos de la idea del nazismo, pero se enfocan con precisión analítica en la función histórica de la fusión de violencia y estética que queda como parte esencial del siglo XX.

\section{La composición sin palabras}

Más allá de su preferencia por transiciones aspecto-a-aspecto, una elección poco frecuente en la historieta según McCloud, Pere Joan también pisa territorio novedoso al construir explicaciones de pictogramas sin usar palabras (véase Beronä 2001). De esta forma, el artista explota la capacidad significadora de la representación icónica en sí, sin necesidad de ofrecer una definición textual como en los ejemplos anteriores (p. ej. \#35 'Lenguajes de síntesis,' \#79 'La política como opio del pueblo' y \#84 'Curar por hablar' [Pere Joan 2014, 46, 95, 99]). El título de 'La política como opio del pueblo' trae a la memoria la frase parecida de Marx comentando la religión y su función ideológica frente al ascenso del capitalismo moderno. Aquí en particular, la ausencia de palabras-con excepción del ejemplo de onomatopeya ('Plas!') y el persistente uso de 'Bla,' el cual contribuye al mismo mensaje-refuerzan la futilidad de la comunicación y la falta de opciones viables con respecto a la esfera pública política. Al dibujar escenas donde candidatos políticos dan discursos televisivos y utilizan revistas para alcanzar al público, Pere Joan utiliza un esquema bicolor enfatizando rojo y azul, colores que efectivamente representan el espectro reducido de opciones políticas en sistemas bipartidistas. Sin verdaderas opciones en la esfera política, una pareja debate el valor de los candidatos en un discurso sin sentido, y en el dibujo final de la urna y dos muchedumbres (una de azul, otra de rojo) no queda duda de que el resultado de la elección sería al fin y al cabo inútil, y preservaría el estatus quo. Por su parte, 'Curar por hablar' retrata una figura humana confesándose a un cura en un contexto religioso católico y a un cerebro en un diván desahogándose frente a un psicoanalista tomando apuntes. El contenido de los círculos-burbujas en los dos contextos sustituye la comunicación verbal, pero en los dos casos, los garabatos dibujados para sustituir palabras ponen en cuestión el propósito de la actividad correspondiente. Dado la falta de calles/paneles y la presencia del espacio abierto expansivo del cuadrado monocolor, las imágenes hasta cierto punto desafían la noción de secuencia o progreso cronológico y tienen el efecto de nivelar la importancia social de ambos, el rito católico y la práctica psicoanalítica.

\section{La composición estilo página}

Sin duda, Pere Joan sigue con una lógica lineal en sus explicaciones de pictogramas aún en los cuadrados de tamaño grande. Sólo que en estos, el autor tiende a utilizar múltiples filas que se leen de izquierda a derecha sin usar líneas de guía. Pese a su clara preferencia lineal, hay algunos números donde rompe con esta lógica puramente lineal para explotar el espacio abierto del cuadrado (p. ej. \#29 'Terrorista,' \#39 'Hedonismo,' 
\#43 El valor joven,” \#45 'Rock, Pop,’ \#47 ‘Omnipresencia de la música,’ \#54 'Electrificación,' y \#69 ‘Ascenso de la clase media y euforia en el vestir' [Pere Joan $2014,42,51,55,57,60,83])$. En estos ejemplos, está claro que los lectores leerán según dos ejes convencionales (de izquierda a derecha; de arriba abajo), pero al ser maximizado el uso del espacio en el cuadrado, ahora el ojo del lector ha sido relativamente liberado de las pautas que suele seguir en el cómic tradicional de paneles y calles.

En dibujos como 'Electrificación,' por ejemplo, el estilo tal vez se asemeja más a la composición de un solo panel con un grupo de representaciones de iluminación icónicas en la parte medio-izquierda superior y el diseño estampado de luces urbanas de noche en la parte de abajo, cerca de los bordes de la esquina derecha. Hay numerosos paneles en los que las imágenes se esparcen por todo el espacio abierto del cuadrado típico monocolor de Pere Joan. Todos estos paneles ostentan la crítica perspicaz del artista en una manera u otra. Por ejemplo, \#99 'Menos, menos' (Pere Joan 2014,113 ) documenta 'la vuelta a lo rural' y sus posibles permutaciones; \#53

‘Superpoblación' (Pere Joan 2014, 68) resalta el impacto de avances en el área de la salud que extienden la vida, y llena una mitad del panel con parejas que dominan el espacio del borde superior al borde inferior; y \#87 'El supermercado' (Pere Joan 2014, 103) documenta y critica en contenido y forma el consumo y su acompañante ilusión de

la abundancia. En estos y otros ejemplos, la extensión de las imágenes comunican el peso social e histórico de la idea que Pere Joan representa en el pictograma escogido.

Pero uno de los ejemplos más intrigantes es 'Ascenso de la clase media y euforia en el vestir' (véase figura 2), escogido no sólo por su composición estilizada sino también por adecuarse a la atención que la semiología prestó a la vestimenta en el siglo XX

y popularizada por teóricos como Roland Barthes (aunque no sin polémica). Dado la compleja composición de la página, los ojos de los lectores tienden a seguir una línea en el centro de la página de arriba abajo, aunque puede también seguir el mismo movi-

miento por el borde izquierdo o el borde derecho del panel. La concentración más densa de imágenes está situada en el mismo centro de la imagen y consiste en un grupo de representaciones de la ropa relativamente desconectadas del texto. El texto aquí sí añade algo, pero las imágenes son aún más poderosas al trazar una progresiva disminución en la distinción visible entre clase alta, clase media, y proletariado a causa de elementos y prácticas igualitarias en la forma de vestir, características del siglo XX: 'El pantalón para la mujer/La camiseta/Los tejanos/El pantalón corto veraniego/

El chándal' (Pere Joan 2014, 83). Hasta cierto punto, las explicaciones textuales que aparecen al pie de la página no añaden mucho a lo ya dibujado en forma icónica arriba, representaciones cuya especificidad no se traduce en palabras sin sacrificar los detalles.

\section{Conclusión}

En 100 pictogramas, Pere Joan demuestra que desde una imagen icónica compacta-tan densa, concreta, comprimida como son los emoticonos, sello distintivo de la comunicación digital y quizá superficial—se puede llegar a una serie de consideraciones sociales, políticas, históricas y tecnológicas. En el mismo proceso, traza la línea de un análisis crítico cuya profundidad de pensamiento inquietantemente tiene validez en la cultura contemporánea digital popular. Con esta obra, Pere Joan resalta la importancia de la interpretación humana en un mundo que cada vez más introduce el mensaje 


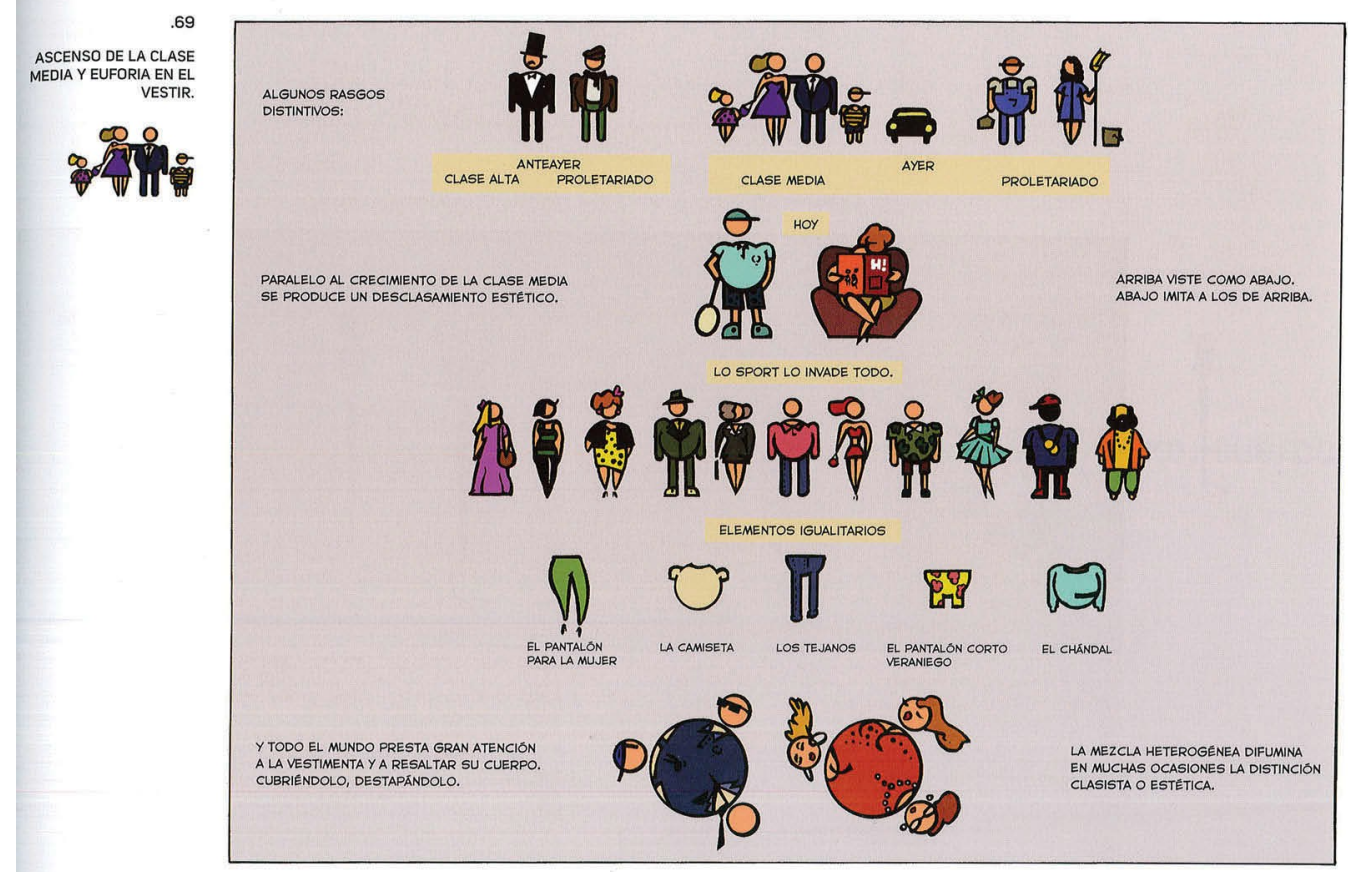

Figura 2. Ascenso de la clase media y euforia en el vestir. 
mecánico en la comunicación entre humanos. Consciente del valor de la enciclopedia en el contexto de la cultura analógica de la imprenta, y casi como tributo a la enciclopedia impresa, Pere Joan afirma que en el siglo XXI sigue siendo necesario pensar profundamente sobre el mundo tecnológico que habitamos, y pensarlo socialmente-para que el conocimiento no sea una afirmación del individualismo sino un recurso colectivo y un bien compartido por los miembros de un pueblo digital común que recuerda su pasado.

\section{Notes}

1. Aunque el comic español en sí queda a los márgenes de los estudios culturales hispanos, existen tratamientos críticos como los de Alary (2000), Gasca y Gubern (2001), Merino (2003, 2009), Prout (2015), Torres (2012), entre otros mencionados en la nota anterior y el primer párrafo del presente ensayo.

2. Según documenta Pablo Dopico, el nombre verdadero de Max es Francesc Capdevila (Dopico 2005, 373-74). Sobre los cómics de ese período en general véanse también Altarriba Ordóñez (2001), Lladó Pol (2001), y Pons, Porcel, y Sorni (2007).

3. 'En contraposición clara a la corriente liderada por El Víbora en ese momento, se pasa de unos planteamientos contraculturales y de rebeldía social frente a lo establecido a otros de pura rebeldía formal nacida del respeto a la tradición francobelga más pura que representa Hergé. Autores como Roger, Montesol, Gallardo, Mariscal, Cifré y Pere Joan firman historias que hacen un papel de crónica social de la Barcelona de los 80' (Pons 2013, 77).

4. El teórico del cómic Román Gubern aclara la importancia del pictograma en la tradición visual del cómic en el capítulo de su importante libro El lenguaje de los cómics (1972) titulado 'La viñeta o pictograma y las microunidades significativas' (véase tmbn. Gasca y Gubern 2001).

5. Publicaciones recientes sobre los emoticonos han investigado su uso en contexto (Dresner y Herring 2010, 252), la comparación de emoticonos y elipsis respecto a la crítica (Thomson y Filik 2016, 116-17) y su relevancia a las user-created cultures (Hjorth 2009b, 1-2). Véase también Filik et al. (2016), sobre la emoción y los emoticonos.

6. Se ha sugerido que en 1912 el escritor Ambrose Bierce, por ejemplo, "proposed a new way to use punctuation in a sentence. He introduces a "period that chuckles" or a symbol that "laughs" featuring the \__ / characters, a symbol for a smile' (Tomić, Martinez, y Vrbanec 2013, 36).

7. Considera que, como bien nota Dresner y Herring, 'The prototypical emoticons are facial expression icons' $(2010,250)$.

8. 'The mobile phone has become both the symbol and vehicle for these transformations around consumption and production paradigms. It is also one of the most personal and intimate objects [...], so much so that it is often personalised to the point of personification (Hjorth 2009b). It is indicative of broader socio-cultural shifts in which the "personal" has become political' (Hjorth 2009a, 65, énfasis original).

9. Existen, claro, detractores del papel desempeñado por los emoticonos en una cultura digital ascendente. Caso en punto: en un interesante y breve ensayo titulado 'Critical Emoticons,' Lynn Z. Bloom - cabe decirlo, no sin una que otra nota de sarcasmo-propone 'an economical system of literary criticism, adapted from that fount (and, I might add, font) of wisdom, the Internet' $(2011,247)$, de tal manera resaltando en lo económico de los emoticonos.

10. Esto es, 'detailed and precise attention to rhetoric, style, language choice, and so forth through a word-by-word analysis of a text's linguistic techniques' (Hayles 2012, 58, esto con atribución a John Guillory).

11. 'Hyper reading has become a necessity. It enables a reader quickly to construct landscapes of associated research fields and subfields' (Hayles 2012, 62).

12. Los lectores notarán también que en las últimas páginas del libro, en una sección titulada ‘Una opinión y un método,' Pere Joan sugiere que el libro es necesariamente inspirado por 
una fusión de lógica analógica y lógica digital. También admite que su respuesta a la pregunta 'qué significa el siglo XX y cuál es su especifidad' ha sido subjetiva (Pere Joan 2014, 119-21).

13. El texto de Pere Joan combate el punto resaltado por Nicholas Carr en The Shallows: What the Internet is Doing to Our Brains (2010), donde el autor confronta los cambios digitales que 'are imperiling our ability to concentrate, leading to superficial thought, diminished capacity to understand complex texts, and a general decline in intellectual capacity' (resumido por Hayles 2012, 2). Algunos críticos arguyen que estos cambios de lectura efectúan cambios en el cerebro que dificultan el sostenimiento del acto de concentrar (Hayles 2012, 62).

14. En su libro documenta la venganza de vinilo, papel, juegos de mesa, y la imprenta en general, pero no menciona el cómic.

15. Cohn (2009) recurre a la obra de Hatfield (2005) y de Groensteen (2007) en su análisis. Nótense que aún en el capítulo de Cohn aquí citado el énfasis todavía queda sobre un formato más o menos tradicional del cómic. Así que él quiere reorientar la crítica del arte secuencial convencional a fijarse en la página, y no necesariamente admite las desviaciones novedosas tales como las produce Joan en 100 pictogramas.

16. Otra vez en 'Yo' utiliza una estrategia parecida-composición lineal, y uso repetitivo de los círculos-burbujas-para subrayar el egoísmo o 'ensimismamiento y notoriedad' que acompaña el individualismo contemporáneo (Pere Joan 2014, 17). El ejemplo de 'Yo' incluye una desviación del modelo puramente lineal de composición en el uso de una pirámide para simbolizar 'ego, independencia, individualidad' que ocupa una gran parte del cuadrado monocolor. Otro buen ejemplo de composición lineal simple sería ‘El hula-hoop' (\#46, Pere Joan 2014, 58).

17. En este sentido, las transiciones que encuentra el lector en 'Encontrarse a sí mismo' son más bien del tipo 'escena-a-escena' en la terminología de McCloud-un tipo de transición que todavía dista mucho de las transiciones viñeta-a-viñeta, acción-a-acción y tema-a-tema que suelen ser mucho más frecuente.

18. 'Se considera el nazismo como la representación del mal absoluto. Al menos en lo que concierne al siglo XX. Esto constituye un importante éxito publicitario. Porque existen otros holocaustos menos referenciados. Pero resulta más elegante el nazismo. Lo es: esteticista y poderosamente visual. La atractiva y horrible representación del mal absoluto. El mal + buenos publicistas. Éxitos en taquilla' (Pere Joan 2014, 76).

\section{Disclosure statement}

No potential conflict of interest was reported by the author.

\section{Notes on contributor}

Benjamin Fraser is Professor and Head of Spanish and Portuguese at the University of Arizona. He is Editor-in-Chief of Hispania, the Executive Editor of the Journal of Urban Cultural Studies, Senior Editor of the Arizona Journal of Hispanic Cultural Studies, and co-editor of the Hispanic Urban Studies. His book, The Art of Pere Joan: Space, Landscape and Comics Form, will be published in 2019 with University of Texas Press.

\section{References}

Abdullah, R., and H. Roger. 2006. Pictograms, Icons \& Signs: A Guide to Information Graphics. Traducido por David H. Wilson. London: Thames and Hudson. Impreso.

Alary, V. 2000. "La historieta en España: entre el futuro y el pasado." En Cuatro lecciones sobre el cómic, editado por A. Ballesteros and C. Duée, 35-66. Cuenca: Ediciones de la Universidad de Castilla-la Mancha. Impreso. 
Altarriba Ordóñez, A. 2001. La España del tebeo. La historieta española de 1940 a 2000. Madrid: Espasa. Impreso.

Barker, J. 2010. "Entrevista con Agustín Fernández Mallo: El mundo a través de cristales, pantallas y libros." Anales de Literatura Española Contemporánea 35 (1): 341-50. Impreso.

Barker, J. 2014. "Agustín Fernández Mallo's Nocilla Project: Seeking Affective Engagement in the World City." Arizona Journal of Hispanic Cultural Studies 18: 31-52. Impreso.

Beronä, D. A. 2001. "Pictures Speak in Comics without Words." In The Language of Comics, edited by R. Varnum and C. T. Gibbons, 19-39. Jackson: University Press of Mississippi. Impreso.

Bloom, L. Z. 2011. "Critical Emoticons." symplokē 18 (1-2): 247-249.

Bufill, J. 1994. "La nueva historieta: de la vanguardia a la comunicación." Catalònia 36: 24-34.

Carr, N. 2010. The Shallows: What the Internet is Doing to Our Brains. New York: W. W. Norton. Impreso.

Cohn, J. 2009. "Mise-en-Page: A Vocabulary for Page Layouts." In Teaching the Graphic Novel, edited by S. E. Tabachnick, 44-57. New York: MLA. Impreso.

Compitello, M. A. 2014. "Sketching the Future Furiously: La Movida, Graphic Design and the Urban Process in Madrid." In Toward a Cultural Archive of La Movida: Back to the Future, edited by W. J. Nichols and H. Rosi Song, 203-232. Madison, NJ: Farleigh Dickinson University Press. Impreso.

Conget, J. M. 2004. "La aventura estética de los tebeos." Pliegos de Yuste 2: 17-24.

de Guereñu, D., and J. Manuel. 2011. "El cómic español desde 1995." ARBOR Ciencia, Pensamiento y Cultura 187: 209-220.

Dopico, P. 2005. El cómic underground español, 1970-1980. Madrid: Cátedra. Impreso.

Dresner, E., and S. C. Herring. 2010. "Functions of the Nonverbal in CMC: Emoticons and Illocutionary Force." Communication Theory 20: 249-268.

Drucker, J. 2014. Graphesis: Visual Forms of Knowledge Production. Cambridge: Harvard University Press. Impreso.

Fernández Mallo, A. 2008. Nocilla Experience. Madrid: Alfaguara. Impreso.

Fernández Mallo, A. 2009. Nocilla Lab. Madrid: Alfaguara. Impreso.

Fernández Mallo, A. [2006] 2010. Nocilla Dream. Barcelona: Candaya. Impreso.

Filik, R., A. Turcan, D. Thompson, N. Harvey, H. Davies, and A. Turner. 2016. "Sarcasm and Emoticons: Comprehension and Emotional Impact." The Quarterly Journal of Experimental Psychology 69 (11): 2130-2146.

Fraser, B. 2012. "On Nocilla and the Urbanization of Consciousness: Multiplicity and Interdisciplinarity in Agustín Fernández Mallo's Fragmented Trilogy." Hispania 95 (1): 1-13. Impreso.

Fraser, B. 2016. "Art and Science in Pere Joan's Nocilla Experience (2011)." Journal of International Comic Art 18 (1): 169-195.

García, S. 2010. La novela gráfica. Bilbao: Astiberri. Impreso.

García, S. 2011. "The Graphic Novel Experience." Mandorla: El blog de cómics de Santiago García, publicado 17 Junio. accedido 21 mayo 2015. http://santiagogarciablog.blogspot.com/2011/06/ graphic-novel-experience.html

Gasca, L., and R. Gubern. 2001. El discurso del cómic. 4a ed. Madrid: Cátedra [Signo e imagen]. Impreso.

Groensteen, T. 2007. The System of Comics. Traducido por Bart Beaty y Nick Nguyen. Jackson: University Press of Mississippi. Impreso.

Gubern, R. 1972. El lenguaje de los comics. Barcelona: Península. Impreso.

Gutiérrez García Huidobro, J. 2014. "Nocilla Experience, la novela gráfica: adaptación y reescritura." Dicenda. Cuadernos de Filología Hispánica 32: 189-204.

Hatfield, C. 2005. Alternative Comics: An Emerging Literature. Jackson: University Press of Mississippi. Impreso.

Hayles, N. K. 2012. How We Think: Digital Media and Contemporary Technogenesis. Chicago: University of Chicago Press. Impreso.

Henseler, C. 2011a. Spanish Fiction in the Digital Age: Generation X Remixed. New York: Palgrave Macmillan. Impreso. 
Henseler, C. 2011b. "Oda a la basura: la poética spam de Agustín Fernández Mallo." Boletín Hispánico Helvético 17-18: 90-104.

Hjorth, L. 2009a. "The Art of Being Novel: Rethinking Cartographies of Personalisation." En Re: Live Media Art Histories Refereed Conference Proceedings, edited by S. Cubitt and P. Thomas, 65-72. Melbourne: University of Melbourne; Victorian College of the Arts and Music.

Hjorth, L. 2009b. "Digital Art in the Age of Social Media: A Case Study of the Politics of Personalization via Cute Culture." Breaking New Ground: Innovation in Games, Play, Practice and Theory. Proceedings of DiGRA 2009 International Conference, Brunel University, London. Accedido mayo 21 2015. http://www.digra.org/digital-library/publications/digital-art-in-the-ageof-social-media-a-case-study-of-the-politics-of-personalization-via-cute-culture/

Lladó Pol, F. 2001. Los cómics de la transición (el boom del cómic adulto 1975-84). Barcelona: Glénat. Impreso.

Lladó Pol, F. 2012. "El cómic a Mallorca durant els anys vuitanta. Un mitjà de renovació cultural." Zeitschrift für Katalanistik 25: 171-200.

McCloud, S. 2009. Entender el cómic. Bilbao: Astiberri. Impreso.

Merino, A. 2003. El cómic hispánico. Madrid: Cátedra. Impreso.

Merino, A. 2009. "The Cultural Dimensions of the Hispanic World Seen through Its Graphic Novels." In Teaching the Graphic Novel, traducido por Derek Petrey y Elizabeth Polli y editado por Stephen E. Tabachnick, 271-280. New York: MLA. Impreso.

Pere Joan. 2011. Nocilla Experience: La novela gráfica. Madrid: Alfaguara. Impreso.

Pere Joan. 2014. 100 pictogramas para un siglo (XX). Alicante: Edicions de Ponent. Impreso.

Pons, Á. 2013. "La nueva escuela valenciana: un ejemplo de renovación formal desde la tradición de la historieta." Eme 1: 72-79.

Pons, A. M., P. Porcel, and V. Sorni. 2007. Viñetas a la luna de Valencia. La historia del tebeo valenciano 1965-2006. Onil: Edicions de Ponent. Impreso.

Prout, R. 2015. "À la recherche du chien perdu: Watch Dogs, Memory, and Mourning in Recuerdos de perrito de mierda (Shitty Little Dog Memories)." International Journal of Comic Art 17 (2): 82-97. Impreso.

Saum Pascual, A. 2014. "La poética de la Nocilla: Transmedia Poetics in Agustín Fernández Mallo's Complete Works." Caracteres. Estudios culturales y críticos de la esfera digital 3 (1): 81-99.

Sax, D. 2016. The Revenge of Analog. New York: Public Affairs/Perseus Books. Impreso.

Thompson, D., and R. Filik. 2016. "Sarcasm in Written Communication: Emoticons are Efficient Markers of Intention." Journal of Computer-Mediated Communication 21: 105-120.

Tomić, M. K., M. Martinez, and T. Vrbanec. 2013. "Emoticons." fiP 1 (1): 35-42.

Torres, S. L. 2012. "Extrañamiento y subversión de la imagen en Dinero de Miguel Brieva." Arizona Journal of Hispanic Cultural Studies 16: 49-65. Impreso.

Vilarós, T. 2002. Mono del desencanto. Una crítica cultural de la transición española 1973-1993. Madrid: Siglo XXI. Impreso.

Wyss, E. L. 1999. "Iconicity in the Digital World: An Opportunity to Create a Personal Image?" In Form Miming Meaning: Iconicity in Language and Literature, edited by M. Nänny and O. Fischer, 285-304. Amsterdam: Benjamins. 